\title{
Corrigendum: Prevalence and clinical characteristics associated with peripheral neuropathy amongst persons on HAART in Busia County, Kenya
}

\begin{tabular}{|c|c|}
\hline \multicolumn{2}{|c|}{$\begin{array}{l}\text { Authors: } \\
\text { John N. Mukoma }{ }^{1} \text { (1) } \\
\text { Joseph M. Matheri' } \\
\text { Nassib Tawa } \\
\text { Not, (D) }\end{array}$} \\
\hline \multicolumn{2}{|c|}{$\begin{array}{l}\text { Affiliations: } \\
{ }^{1} \text { Department of } \\
\text { Physiotherapy, Busia } \\
\text { County Referral Hospital, } \\
\text { Busia, Kenya }\end{array}$} \\
\hline \multicolumn{2}{|c|}{$\begin{array}{l}{ }^{2} \text { Department of } \\
\text { Physiotherapy, College of } \\
\text { Health Sciences, Jomo } \\
\text { Kenyatta University of } \\
\text { Agriculture and Technology, } \\
\text { Nairobi, Kenya }\end{array}$} \\
\hline \multicolumn{2}{|c|}{$\begin{array}{l}{ }^{3} \text { Center for Research in Spinal } \\
\text { Health and Rehabilitation } \\
\text { Medicine, Department of } \\
\text { Physiotherapy, College of } \\
\text { Health Sciences, Jomo } \\
\text { Kenyatta University of } \\
\text { Agriculture and Technology, } \\
\text { Nairobi, Kenya }\end{array}$} \\
\hline \multicolumn{2}{|c|}{$\begin{array}{l}{ }^{4} \text { Department of Health and } \\
\text { Rehabilitation Sciences, } \\
\text { Stellenbosch University, Cape } \\
\text { Town, South Africa }\end{array}$} \\
\hline \multicolumn{2}{|c|}{$\begin{array}{l}\text { Corresponding author: } \\
\text { John Mukoma, } \\
\text { mukoshjn19@gmail.com }\end{array}$} \\
\hline \multicolumn{2}{|c|}{$\begin{array}{l}\text { Date: } \\
\text { Published: } 26 \text { Nov. } 2021\end{array}$} \\
\hline \multicolumn{2}{|c|}{$\begin{array}{l}\text { How to cite this correction: } \\
\text { Mukoma, J.N., Matheri, J.M. } \\
\text { \& Tawa, N., 2021, } \\
\text { 'Corrigendum: Prevalence } \\
\text { and clinical characteristics } \\
\text { associated with peripheral } \\
\text { neuropathy amongst persons } \\
\text { on HAART in Busia County, } \\
\text { Kenya', South African Journal } \\
\text { of Physiotherapy 77(1), } \\
\text { a1615. https://doi.org/ } \\
\text { 10.4102/sajp.v77i1.1615 }\end{array}$} \\
\hline \multirow[b]{2}{*}{ 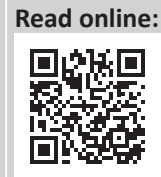 } & \\
\hline & $\begin{array}{l}\text { Scan this QR } \\
\text { code with your } \\
\text { smart phone or } \\
\text { mobile device } \\
\text { to read online. }\end{array}$ \\
\hline
\end{tabular}

In the version of this article initially published, Mukoma, J.N., Matheri, J.M. \& Tawa, N., 2020, 'Prevalence and clinical characteristics associated with peripheral neuropathy amongst persons on HAART in Busia County, Kenya', South African Journal of Physiotherapy 76(1), a1430. https:/ / doi. org/10.4102/sajp.v76i1.1430, the affiliations for the third author, Nassib Tawa, was given incorrectly in the 'Authors' and 'Affiliations' sections. The author's affiliations are now corrected as:

\author{
Authors: \\ John N. Mukoma ${ }^{1}$ (D) \\ Joseph M. Matheri ${ }^{2} \bullet$ \\ Nassib Tawa ${ }^{3,4}$ \\ Affiliations: \\ ${ }^{1}$ Department of Physiotherapy, Busia County Referral Hospital, Busia, Kenya \\ ${ }^{2}$ Department of Physiotherapy, College of Health Sciences, Jomo Kenyatta University of Agriculture and \\ Technology, Nairobi, Kenya \\ ${ }^{3}$ Center for Research in Spinal Health and Rehabilitation Medicine, Department of Physiotherapy, \\ College of Health Sciences, Jomo Kenyatta University of Agriculture and Technology, Nairobi, Kenya \\ ${ }^{4}$ Department of Health and Rehabilitation Sciences, Stellenbosch University, Cape Town, South Africa
}

This correction does not alter the study's findings of significance or overall interpretation of the study's results. The authors apologise for any inconvenience caused.

Copyright: (C) 2021. The Authors. Licensee: AOSIS. This work is licensed under the Creative Commons Attribution License. Note: DOI link to the original article: https://doi.org/10.4102/sajp.v76i1.1430 


\section{Prevalence and clinical characteristics associated with peripheral neuropathy amongst persons on HAART in Busia County, Kenya}

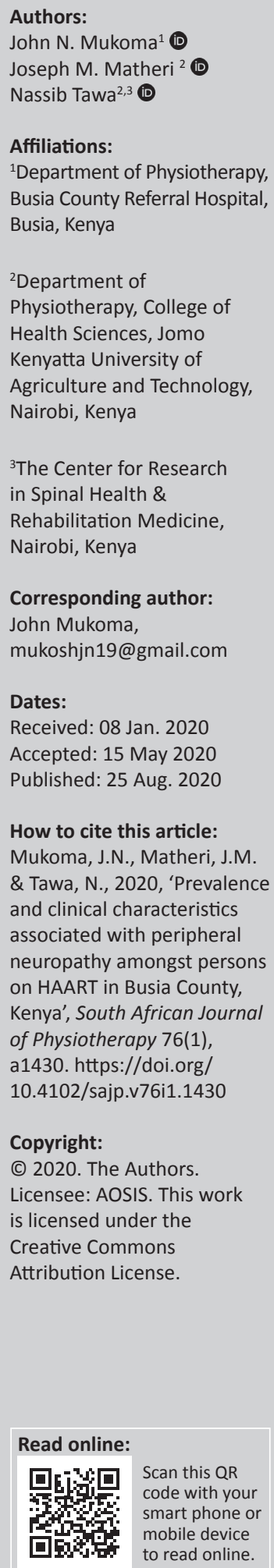

Background: Despite improved immunological and viral load control, the prevalence of HIV/AIDS-related peripheral neuropathy among survivors on highly active antiretroviral therapy (HAART) is rising globally raising public health concerns.

Objectives: To determine the prevalence and clinical characteristics of peripheral neuropathy amongst persons on HAART attending Comprehensive Care Clinics in Busia County, Kenya.

Method: This cross-sectional descriptive quantitative study utilised purposive sampling and included 289 adults living with HIV / AIDS. Data collection was undertaken using the Clinical HIV Associated Neuropathy Tool (CHANT) and analysed using the Statistical Package for the Social Sciences version 25.0.

Results: Of people on HAART, 68.17\% (197 amongst 289) had peripheral neuropathy. The majority were female $76.8 \%(n=222), 38.1 \%(n=110)$ were between 41 and 50 , and $35 \%$ $(n=101)$ were widowed. The most common primary symptom was reduced right foot big toe vibration $(76.8 \%, n=222)$. There was a strong positive relationship $(r=0.621, P=0.000)$ between foot vibration and illness. There was a statistically significant influence of demographic characteristics of persons on HAART on PN as they accounted for $98.5 \%$ of the variance $\left(R^{2}=0.985\right)$.

Conclusion: Peripheral neuropathy is prevalent and is significantly influenced by sociodemographic characteristics of persons on HAART-PN. Early diagnosis and exercise guidance by physiotherapists is key in forestalling severe symptoms, disability and poor quality of life.

Clinical implications: There is need to screen persons living with HIV on HAART for PN to establish their medical, physiotherapy and rehabilitation needs. Early diagnosis will encourage healthcare workers to start interventions to prevent progression of impairment, onset of disability and decrease in quality of life. Therefore, adaptation of PN screening tools and physiotherapeutic interventions should be considered.

Keywords: clinical symptoms; HAART; HIV-related peripheral neuropathy; CHANT; physiotherapy.

\section{Introduction}

The prevalence of peripheral neuropathies amongst seroreactive persons is increasing globally raising public health concerns (Aminoff \& Portegies 2007; Choi et al. 2011; Wulff, Wang \& Simpson 2000). Peripheral neuropathy (PN) is defined as the presence of either a pain or burning sensation, aching or numbness combined with the absence of reflexes or impairment resulting from a vibration sensation in the great toe (Evans et al. 2011). Globally, between 30\% and $60 \%$ of individuals with HIV are diagnosed with neuropathic conditions. With the improved use of chemoprophylaxis highly active antiretroviral therapy (HAART), the prevalence of HIV-related neuropathies resulting from HIV / AIDS has greatly changed (Evans et al. 2011; Ferrari et al. 2006; Mehta et al. 2011). In a study to determine the outcomes of HIV infection on the nervous system, Aminoff and Portegies (2007) noted that although there was a decline in the incidence of HIV-related neuropathies, the prevalence of neurological impairments and disability has increased significantly due to the improved survival of persons with HIV / AIDs accessing and using HAART.

Though seldom seen in children, $\mathrm{PN}$ is the commonest neurological problem amongst adults who are infected with HIV (Colloca et al. 2017; Keltner et al. 2012). Tumusiime et al. (2014) noted that 
PN currently affects persons living with HIV as a complication of both HIV and ART.

Whereas HIV associated 'distal symmetrical polyneuropathy' is a common neurological problem, variable incidences of its occurrences, ranging from $19 \%$ to $66 \%$, are reported (Afzal et al.2015). Moreover, HIV-associated peripheral neuropathies are often misdiagnosed or the diagnosis is overlooked (Wulff et al. 2000).

There is also a growing body of evidence linking the use of antiretroviral agents (HAART) to neuropathic diseases (Attal \& Bouhassira 2015). For instance, Wulff et al. (2000) noted that distal symmetrical polyneuropathy is a frequent type of PN reported amongst persons with HIV infection who have neurotoxic levels of antiretroviral agents or advanced immunosuppression. In the USA, where HAART is readily available, the greatest proportion of the neuropathic disease burden is $\mathrm{PN}$ and HIV-associated cognitive dysfunction (Ellis et al. 2010). In contrast, in low-tomiddle income countries where HAART is not readily available, opportunistic infections of the central nervous system account for the greatest proportion of the reported neuropathic disease burden (Kongsiriwattanakul \& Suankratay 2011). In a cross-sectional study, conducted in Bangkok, Thailand, to determine the frequency of sensory neuropathy amongst 118 HIV-positive patients, Sithinamsuwan et al. (2008) found a $28 \%$ possibility of sensory neuropathy amongst those not on HAART. Cashman and Hoke (2015) observed that regardless of the improved control of the virus in the past decade, the incidence of neuropathy amongst HIV/AIDS patients significantly increased from 13\% in 1993 to 50\% in 2015.

Most of these studies were conducted in developed countries including the USA, and the UK (Aminoff \& Portegies 2007; Evans et al. 2011). In Central Africa, the first verifiable case of HIV / AIDS was reported in 1983, as noted by Song'ony (2008). The spread of HIV/AIDS has been blamed on globalisation including migration, trade and travel (Todrys \& Amon 2009). Civil unrest in countries like Uganda, the Democratic Republic of Congo (DRC), and South Africa is also believed to have brought HIV / AIDS to new locations as a result of large-scale migration (WHO 2018). Unlike in the USA and other European countries, African victims have a higher incidence of transmittance of the virus through heterosexual intercourse than from homosexuality or drug addiction (Song'ony 2008). In subSaharan Africa, little information is available concerning the impact of HIV / AIDS-related neuropathy, ensuing disability and the quality of life challenges amongst survivors of HIV. However, in a cross-sectional study, involving 800 HIV-positive participants, conducted in Uganda, to assess risk factors, prevalence, and neuropathies-related disabilities, Saylor et al. (2017) found a 19\% prevalence rate of peripheral neuropathy amongst them. Therefore, the aim of our study was to determine the prevalence, and the clinical characteristics associated with PN amongst persons on HAART attending a Comprehensive Care Clinic in Busia
County, Kenya. The information generated from our study on the burden and clinical characteristics associated with PN could possibly contribute to practice, implementation of health and disability policies including planning and provision of rehabilitation services.

\section{Method}

Our study was undertaken at the Comprehensive Care Clinics (CCC) in Busia County one of the 47 counties in Kenya. In the 2009 National Census, Busia County had an estimated population of 823504 which is $1.9 \%$ of the national population, with most of the population being female (52\%). The county's poverty level was $64.2 \%$ compared to the National poverty level of $45.9 \%$. It had an estimated 164701 households with an average family size of 5 and a literacy level of $75.3 \%$ amongst those aged 16 years and above.

Our cross sectional study utilised quantitative methods for data collection. We considered the population of all adults of both genders aged 20 to 68 years, with HIV infection and on HAART, who were living in Busia County. The Kenya HIV county profiles (2016) reported that Busia County had 38549 people infected with HIV/AIDS. According to the same report, there were more female persons $(8.3 \%)$ than male (5.0\%). Persons on HAART care were spread over 67 CCC. According to the 2018 Kenya guidelines for treating and preventing HIV, patients testing positive for HIV are given $\mathrm{AZT}+3 \mathrm{TC}+\mathrm{EPV}$ or $\mathrm{RAL}, \mathrm{ABC}+3 \mathrm{TC}+\mathrm{LPV} / \mathrm{r}, \mathrm{AZT}+3 \mathrm{TC}$ $+\mathrm{EPV}$ (or RAL), TDF + 3TC + ATV $/ \mathrm{r}, \mathrm{AZT}+3 \mathrm{TC}+\mathrm{DTG}$ (or $\mathrm{EPV}), \mathrm{TDF}+3 \mathrm{TC}+\mathrm{ATV} / \mathrm{r}^{2}$ as either first- or second-line HAART treatments.

A simple random technique was used to select study sites from the 67 CCC, which resulted in four sites being selected. Further, purposive sampling conducted in the selected sites resulted in 300 potential participants on HAART being recruited between the months of March and April 2019.

A piloted version of the validated Clinical HIV Associated Neuropathy Tool (CHANT) was used to assess symptoms (pain, numbness, ankle reflexes and vibration sense) to establish the presence of PN amongst persons living with HIV and on HAART. Piloting was done to assess the user friendliness of the CHANT tool before adopting it. According to the developers, the CHANT tool was validated clinically and field tested on seropositive clients in the UK and in Johannesburg, South Africa (Woldeamanuel et al. 2016).

In both the South African and the UK samples it recorded good sensitivity $=74 \%$, specificity $=85 \%$, internal consistency $=0.88$ (Cronbach's alpha) and inter-item correlation $=0.73$ (Spearman's Rho) and inter-rater agreement $>0.93$ (Spearman's Rho).

\section{Statistical analysis}

Data were entered into MS Excel and imported to the Statistical Package for Social Sciences (SPSS) software 
for analysis. Descriptive statistics for demographic variables (including gender, level of education, marital status and illness) were calculated based on the frequencies and percentage distributions. A correlation analysis using Pearson's product-moment correlation $(r)$ was used to analyse the relationship between the demographic characteristics and prevalence distribution of PN. The statistical influence of demographic characteristics on PN amongst persons on HAART was further analysed by an analysis of variance as well as a linear regression analysis at a significance level of $p<0.005$.

\section{Ethical consideration}

The study obtained ethical clearance from Jomo Kenyatta University of Agriculture and Technology (JKUAT) Ethical Review Committee (REF: JKU/2/4/896B) and was approved by the National Commission of Science, Technology and Innovation (NACOSTI/P/19/146317/29284).

\section{Results}

Out of the 300 questionnaires administered, 289 were completed correctly whilst 11 had incomplete data and were discarded. This resulted in a $96.33 \%$ response rate. Of the 289 respondents, $76.8 \%(n=222)$ were female. Thirty-eight $(38.1 \% n=110)$ were middle-aged adults between 41 and 50, followed by those-aged 51 and above, 36\% ( $n=104)$. Additionally, $35 \%(n=101)$ were widowed whilst only $28 \%$ $(n=81)$ were married. The majority of the respondents, $53.6 \%$ $(n=155)$, had primary school education, and $27.7 \%(n=80)$ had secondary school education (Table 1).

\begin{tabular}{|c|c|c|c|}
\hline Demographic variables & Characteristics & Frequency & Percentage $\%$ \\
\hline \multirow[t]{3}{*}{ Gender } & Male & 67 & 23.2 \\
\hline & Female & 222 & 76.8 \\
\hline & Total & 289 & 100.0 \\
\hline \multirow[t]{6}{*}{ Age } & $\leq 20$ years & 10 & 3.5 \\
\hline & $21-30$ years & 18 & 6.2 \\
\hline & $31-40$ years & 47 & 16.3 \\
\hline & $41-50$ years & 110 & 38.1 \\
\hline & $\geq 50$ years & 104 & 35.9 \\
\hline & Total & 289 & 100.0 \\
\hline \multirow[t]{5}{*}{ Education } & No formal school & 47 & 16.3 \\
\hline & Primary school & 155 & 53.6 \\
\hline & Secondary school & 80 & 27.7 \\
\hline & Tertiary & 7 & 2.4 \\
\hline & Total & 289 & 100.0 \\
\hline \multirow[t]{7}{*}{ Marital status } & Single & 32 & 11.1 \\
\hline & Married & 81 & 28.0 \\
\hline & Cohabiting & 42 & 14.5 \\
\hline & Separated & 18 & 6.2 \\
\hline & Divorced & 15 & 5.2 \\
\hline & Widowed & 101 & 35.0 \\
\hline & Total & 289 & 100.0 \\
\hline \multirow[t]{3}{*}{ Illness } & With illness & 197 & 68.2 \\
\hline & Without illness & 92 & 31.8 \\
\hline & Total & 289 & 100.0 \\
\hline
\end{tabular}

Source: Primary data

\section{Prevalence of peripheral neuropathy amongst males and females on HAART}

Symptomatic PN had a prevalence of $68.1 \% \%$ (197 of 289 ). Illness was independently associated with the development of PN amongst the participants. The primary signs and symptoms reported by participants with PN were reduced right foot big toe vibration (76.8\%, 222 of 289), right foot pain $(69.55 \%, 201$ of 289) followed by right ankle reflex reduction $(74.7 \%, 216$ of 289$)$. Men had right foot pain $(n=41,14.19 \%)$, left foot pain $12.80 \%(n=37)$, right foot numbness $15.92 \%(n=46)$, left foot numbness, $15.22 \%$ $(n=44)$, reduced right foot vibration $22.83 \%(n=66)$, left foot vibration $22.15 \%(n=64)$, right ankle reflex reduction $23.18 \%$ $(n=67)$ and left ankle reflex reduction $21.80 \%(n=63)$. Women had right foot pain $(n=160,55.36 \%)$, left foot pain $53.29 \%(n=154)$, right foot numbness $50.52 \%(n=146)$, left foot numbness $49.13 \%(n=142)$; reduced right foot vibration $53.97 \%(n=156)$, reduced left foot vibration $54.33(n=157)$, right ankle reflex reduction $51.56 \%(n=149)$ and left ankle reflex reduction $51.90 \%(n=150)$ (Table 2$)$.

\section{Relationship between peripheral neuropathy and demographic characteristics}

The results indicate that there was some relationship between PN and demographic characteristics. The results illustrated in Table 3 show a strong positive relationship $(r=0.837$, $p=0.000$ ) between foot pain and illness.

There was a weak positive relationship between age, gender, education as well as marital status and foot pain.

Similarly there was a strong positive $(r=0.896, p=0.0001)$ relationship between foot numbness and illness, and the relationship between age, gender, education, marital status and foot numbness was positive but weak. There was a

TABLE 2: Prevalence of peripheral neuropathy amongst male and female participants on HAART.

\begin{tabular}{lcccccc}
\hline PN diagnostic indicators & \multicolumn{2}{c}{ With PN } & & \multicolumn{2}{c}{ Without PN } \\
\cline { 2 - 3 } \cline { 5 - 6 } & $\boldsymbol{n}=\mathbf{1 9 7}$ & $\mathbf{\%}$ & & $\boldsymbol{n}=\mathbf{9 2}$ & $\mathbf{\%}$ \\
\hline Male ( $\boldsymbol{n}=\mathbf{6 7}$ ) & 41 & 14.19 & & 26 & 9.0 \\
Right foot pain & 37 & 12.80 & & 30 & 10.38 \\
Left foot pain & 46 & 15.92 & & 21 & 7.27 \\
Right foot numbness & 44 & 15.22 & & 23 & 7.96 \\
Left foot numbness & 66 & 22.83 & & 1 & 0.35 \\
Right foot big toe vibration & 64 & 22.15 & & 3 & 1.04 \\
Left foot big toe vibration & 67 & 23.18 & & 0 & 0 \\
Right ankle reflex & 63 & 21.80 & & 4 & 1.38 \\
Left ankle reflex & & & & & \\
Female ( $\boldsymbol{n}=\mathbf{2 2 2}$ ) & 160 & 55.36 & & 62 & 21.45 \\
Right foot pain & 154 & 53.29 & & 68 & 23.53 \\
Left foot pain & 146 & 50.52 & & 76 & 26.30 \\
Right foot numbness & 142 & 49.13 & & 80 & 27.68 \\
Left foot numbness & 156 & 53.97 & & 6 & 2.08 \\
Right foot big toe vibration & 157 & 54.33 & & 5 & 1.73 \\
Left foot big toe vibration & 149 & 51.56 & & 3 & 1.04 \\
Right ankle reflex & 150 & 51.90 & & 2 & 0.69 \\
Left ankle reflex & & & & \\
\hline
\end{tabular}

Source: Primary data

PN, peripheral neuropathy. 
strong positive $(r=0.621, p=0.000)$ relationship between foot vibration sense loss and illness. There was a weak positive relationship between age, gender, education as well as marital status and foot vibration sense loss. There was a moderate positive $(r=0.541, p=0.0001)$ relationship between ankle reflex reduction and illness. Similarly, there was a weak positive relationship between age, gender, education as well as marital status and reduced ankle reflex. The results indicate

TABLE 3: Relationship between demographic characteristics $(n=289)$ and peripheral neuropathy.

\begin{tabular}{lcccc}
\hline Characteristics & Foot pain & Foot numbness & Foot vibration & Ankle reflex \\
\hline Age & & & & \\
Pearson correlation & $0.331 \dagger$ & 0.221 & 0.026 & 0.069 \\
Sig. (2-tailed) & 0.000 & 0.000 & 0.000 & 0.000 \\
$N$ & 289 & 289 & 289 & 289 \\
Gender & & & & \\
Pearson correlation & 0.026 & 0.026 & 0.033 & 0.056 \\
Sig. (2-tailed) & 0.000 & 0.000 & 0.000 & 0.000 \\
$N$ & 289 & 289 & 289 & 289 \\
Education & & & & \\
Pearson correlation & 0.083 & 0.013 & $0.670 \dagger$ & 0.024 \\
Sig. (2-tailed) & 0.000 & 0.000 & 0.000 & 0.000 \\
$N$ & 289 & 289 & 289 & 289 \\
Marital status & & & & \\
Pearson correlation & $0.483 \dagger$ & $0.308 \dagger$ & 0.084 & 0.016 \\
Sig. (2-tailed) & 0.000 & 0.000 & 0.000 & 0.000 \\
$N$ & 289 & 289 & 289 & 289 \\
Illness & & & & \\
Pearson correlation & $0.837 \dagger$ & $0.896 \dagger$ & $0.621 \dagger$ & $0.541 \dagger$ \\
Sig. (2-tailed) & 0.000 & 0.000 & 0.000 & 0.000 \\
$N$ & 289 & 289 & 289 & 289 \\
\hline$S O u r c:$ Prit & & & &
\end{tabular}

Source: Primary data

$\uparrow$, Correlation is significant at the 0.05 level (2-tailed).

$\$$, Correlation is significant at the 0.01 level (2-tailed). a strong and positive relationship $(r=0.670, p=0.00)$ between foot vibration and education. Thus, it can be argued that there was a strong relationship between PN (foot pain, foot numbness, foot vibration sense and ankle reflex) and illness.

Table 3 summarises the relationship between the participants' $(n=289)$ demographic characteristics and PN.

\section{Influence of peripheral neuropathy amongst persons on HAART}

Table 4 shows that there was a statistically significant influence on the PN domain and demographic characteristics of people on HAART as they accounted for $98.5 \%$ of the variation $\left(R^{2}=0.985\right)$.

Further, the overall model also reveals a statistically significant relationship between the PN domain and demographic characteristics of persons on HAART $(F=3.306, p=0.029)$. The standardised regression coefficient also shows that peripheral neuropathies in persons on HAART are statistically significant. The Beta coefficient for the peripheral neuropathy domain was found to be positive and statistically significant. The regression results are summarised in Table 4.

\section{Discussion}

The improved survival of persons with HIV/AIDS on HAART has seen an increase in the prevalence of neurological conditions (Ferrari et al. 2006; Mehta et al. 2011; Wolfe \& Barohn 2002). The results of our study confirm that PN is prevalent amongst persons on HAART in Busia County.

TABLE 4a: Regression results of demographic characteristics and peripheral neuropathy domains. (a) Goodness-of-fit.

\begin{tabular}{|c|c|c|c|c|c|c|c|c|c|}
\hline \multirow[t]{2}{*}{ Model } & \multirow[t]{2}{*}{$R$} & \multirow[t]{2}{*}{$R$ square } & \multirow[t]{2}{*}{ Adjusted $R$ square } & \multirow[t]{2}{*}{ Std. error of the estimate } & \multicolumn{5}{|c|}{ Change statistics } \\
\hline & & & & & $R$ square change & $F$ change & df1 & df2 & Sig. $F$ change \\
\hline 1 & $0.993 \dagger$ & 0.985 & 0.985 & 0.183 & 0.985 & 0.289 & 10 & 278 & 0.000 \\
\hline
\end{tabular}

Source: Primary data

$\dagger$, Predictors, (Constant).

TABLE 4b: Regression results of demographic characteristics and peripheral neuropathy domains. (b) Overall significance.

\begin{tabular}{llcccc}
\hline Model & & Sum of squares & Df & Mean square & Sig. \\
\hline 1 & Regression & 30.245 & 10 & 3.0245 & $0.029 \dagger$ \\
& Residual & 226.585 & 276 & 0.8210 & -306 \\
& Total & 256.830 & 286 & - & - \\
\hline
\end{tabular}

Source: Primary data

$\dagger$, Dependent variable: Peripheral neuropathy.

TABLE 4c: Regression results of demographic characteristics and peripheral neuropathy domains. (c) Individual significance.

\begin{tabular}{|c|c|c|c|c|c|c|c|c|}
\hline \multirow{2}{*}{\multicolumn{2}{|c|}{ Model }} & \multicolumn{2}{|c|}{ Un-standardised coefficients } & \multicolumn{3}{|c|}{ Standardised coefficients } & \multicolumn{2}{|c|}{$95.0 \%$ confidence interval for $B$} \\
\hline & & $B$ & Std. error & Beta & $T$ & Sig. & Lower bound & Upper bound \\
\hline \multirow[t]{8}{*}{1} & (Constant) & 0.129 & 0.148 & - & 0.876 & 0.382 & 0.420 & 0.161 \\
\hline & Right foot pain & 0.008 & 0.184 & 0.002 & 0.042 & 0.036 & 0.371 & 0.355 \\
\hline & Left foot pain & 0.022 & 0.098 & 0.007 & 0.229 & 0.019 & 0.214 & 0.170 \\
\hline & Right foot numbness & 0.018 & 0.194 & 0.006 & 0.095 & 0.002 & 0.400 & 0.363 \\
\hline & Left foot numbness & 0.024 & 0.098 & 0.008 & 0.248 & 0.004 & 0.168 & 0.216 \\
\hline & Left foot big toe vibration & 0.407 & 0.124 & 0.045 & 3.27 & 0.001 & 0.162 & 0.652 \\
\hline & Right ankle reflex & 0.112 & 0.217 & 0.008 & 0.517 & 0.006 & 0.540 & 0.315 \\
\hline & Left ankle reflex & 0.322 & 0.126 & 0.031 & 2.550 & 0.001 & 0.073 & 0.570 \\
\hline
\end{tabular}

Source: Primary data 
The high prevalence of PN symptoms in our sample is an indication of a growing sub-population at risk of disability and reduced quality of life (Biraguma \& Rhoda 2012; Colloca et al. 2017; Keltner et al. 2012).

Disability arising from HIV has been linked to reduced physical functioning which impacts on activities of daily living in various ways (Biraguma \& Rhoda 2012; Cade, Peralta \& Keyser 2004; Mehta et al. 2010). The unearthing of the prevalence of $\mathrm{PN}$ is critical for clinical care, physiotherapy and the rehabilitation of persons with HIV on HAART in scarcely resourced settings, particularly in Kenya.

This is the first study to report the prevalence and clinical characteristics associated with PN amongst seropositive people on ART medication in Busia County which is a resource-limited setting. The high prevalence $(68 \%)$ of neuropathy amongst the respondents is similar to the study by Tumusiime et al. (2014) which found a 59\% prevalence of PN in Rwanda, and to studies that show a 57\% (226 of 395) (Wadley et al. 2011) prevalence rate of PN amongst people on HAART. Biraguma and Rhoda in their Rwandan study (2012) found that $40.5 \%$ of participants had $\mathrm{PN}$, which again is similar to our study. Other studies have found PN common (over 40\%) amongst ambulatory seropositive persons (Choi et al. 2011; Mbuya et al. 1996; Nicholas et al. 2007; Smyth et al. 2007). However, in a UK study, Skopelitis et al. (2006) reported that PN affected $36 \%$ of participants, and in an Ethiopian study Shurie and Deribew (2010) found that it affected 34.5\% of patients on HAART. These figures are lower than those in our study and could be attributed to the different dynamics of the participants and the measures used to collect data (i.e. clinical presentation versus electrophysiological tests).

Persons on HAART with PN mainly experienced pain, a burning sensation or aching followed by numbness, whilst the most infrequent symptoms were pins and needles. The symptoms in our population were mild (no debilitating condition) in a large number of the respondents with PN (135 out of 289). Pain and illness had a strong positive relationship ( $r=0.837, p=0.000$ ); this implies that pain was culturally perceived as an illness which had the potential to interrupt mobility, social interactions, work or schooling and overall quality of life.

Evidence in support of this view shows that HIV-associated neuropathic pain is common amongst persons living with HIV (Keltner et al. 2012; Wallace et al., 2007) and is associated with pain catastrophising and poor adherence to prescribed medication (Lucey et al. 2011). Moreover, it is related to poor outcomes and problematic treatment choices and a decreased quality of life (Ellis et al. 2010; Keltner et al. 2012) partly due to inappropriate classification, increased drug prescriptions (Attal \& Bouhassira 2015; Wolfe \& Barohn 2002) and visits to physicians as well as the illness from the pain itself and aggravating conditions (Colloca et al. 2017). Individuals usually feel a combination of symptoms, such as electric-like and burning sensations and pain from trivial (non-noxious) stimulation such as light touch (Colloca et al. 2017).
Further, clinical expression of neuropathic pain results in impairment of inhibitory modulation systems, anxiety and depression (Colloca et al. 2017; Keltner et al. 2012; Malvar et al. 2015) which have been associated with sleep problems (Colloca et al. 2017; Sandoval, Runft \& Roddey 2010) and opioid use disorders (Malvar et al. 2015). According to Malvar et al. (2015) factors such as opioid use disorder, older age, being female, current and past ART treatment as well as a lack of HIV suppression predict neuropathic pain (Malvar et al. 2015).

This implies that the neuropathic pain mechanism and its accompanying complications are different from inflammatory pain caused by conditions such as rheumatoid arthritis, and therefore its treatment approaches and choices should differ (Keltner et al. 2012). This notwithstanding, our findings are different from those of Konchalard and Wangphonpattanasiri (2007) who established that numbness was the dominant symptom in most or all forms of neuropathy related to HIV.

It has been suggested that pain and paraesthesia may be early indicators of the disease, whilst numbness becomes apparent as the disease advances. Severity of $\mathrm{PN}$ in persons on HAART can range from mild discomfort to an incapacitating disorder, causing the individual difficulty in walking or even in standing from sitting (Keltner et al. 2012; Schifitto et al. 2002). Many persons with mild PN do not suffer any symptoms, although severe symptoms mostly occur in persons with advanced immunosuppression (Simpson \& Cikurel 2006). The severe symptoms, such as ageing and other comorbidities amongst persons using ART, increase the risk of disability which impacts on multiple aspects of daily living (Biraguma \& Rhoda 2012; Cade et al. 2004; Mehta et al. 2010). Management of symptoms or impairments (such as neuropathic pain), using splints (Sandoval et al. 2010) and physiotherapist-supervised exercise, has shown promising outcomes (Taylor et al. 2007; Tumusiime et al. 2019). This has the potential to influence the deployment of physiotherapists and other rehabilitation professions in universal health care and practice where exercise becomes a key strategy to prevent disability and activity limitation.

A limitation of this study was that neither the key pointers of the illness progression, such as the CD4 count and viral load, nor data on medication for tuberculosis were assessed. Hence, no association between the progression of the illness, manifestation and severity of PN could be established. Our study did not look into other risk factors of PN such as diabetes or poor nutrition.

\section{Implications}

Our study established the presence of PN clinical symptoms in a proportion of the respondents, which has implications for functional status, participation in core activity domains 
and quality of life. There are therefore implications for use of validated early screening tools, diagnosis and management of PN clinical symptoms and complications to mitigate functioning loss or disablement in which physiotherapists and allied rehabilitation professionals have a role to play. Further, there is an implication for physiotherapy research to generate evidence on the effects of physical exercise on clinical symptoms and complications of $\mathrm{PN}$, and the scope of practice.

\section{Conclusion}

In conclusion, $\mathrm{PN}$ is prevalent amongst persons on HAART and is characterised by pain, numbness, decreased ankle tendon reflexes and vibration sense of the big toe, predominantly. Whilst diagnosis of $\mathrm{PN}$ amongst patients on HAART remains generally clinical, other illnesses that complicate distal neuropathies should be excluded. However, early diagnosis and exercise guided by physiotherapists have a higher likelihood of success in preventing progression to impaired function, disability and poor quality of life.

\section{Acknowledgements}

I acknowledge all the respondents without whom this work would not materialise and also the data clerks that played their role with integrity.

\section{Competing interests}

The authors have declared that no competing interests exist.

\section{Authors' contributions}

J.N.M. was the lead author with the guidance of his able co-authors (J.M.M. and N.T.) and so do hereby declare that all the contributions saw this work to completion.

\section{Funding information}

This research received no specific grant from any funding agency in the public, commercial or not-for-profit sectors.

\section{Data availability statement}

Data sharing is not applicable to this article.

\section{Disclaimer}

The views and opinions expressed in this article are those of the authors and do not necessarily reflect the official policy or position of any affiliated agency of the authors.

\section{References}

Afzal, A., Benjamin, M., Gummelt, K.L., Afzal, S., Shamim, S. \& Tribble, M., 2015 'Ascending paralysis associated with HIV infection', Proceedings (Baylor University. Medical Center) 28(1), 25-28. https://doi.org/10.1080/08998280. 2015.11929176

Aminoff, M.J. \& Portegies, P., 2007, HIV/AIDS and the nervous system, Elsevier, Edinburgh.

Attal, N. \& Bouhassira, D., 2015, 'Pharmacotherapy of neuropathic pain: Which drugs, which treatment algorithms?', Pain 156, S104-S114. https://doi.org/10.1097/01.j. pain.0000460358.01998.15
Biraguma, J. \& Rhoda, A., 2012, 'Peripheral neuropathy and quality of life of adults living with HIV/AIDS in the Rulindo district of Rwanda', SAHARA-J: Journal of Socia Aspects of HIV/AIDS 9(2), 88-94. https://doi.org/10.1080/17290376.2012.683582

Cade, W.T., Peralta, L. \& Keyser, R.E., 2004, 'Aerobic exercise dysfunction in human immunodeficiency virus: A potential link to physical disability', Physical Therapy 84(7), 655-664. https://doi.org/10.1093/ptj/84.7.655

Cashman, C.R. \& Höke, A., 2015, 'Mechanisms of distal axonal degeneration in peripheral neuropathies', Neuroscience Letters 596, 33-50. https://doi.org/10. 1016/j.neulet.2015.01.048

Choi, Y., Townend, J., Vincent, T., Zaidi, I., Sarge-Njie, R., Jaye, A. et al., 2011 'Neurologic manifestations of human immunodeficiency virus-2: Dementia, myelopathy, and neuropathy in West Africa', Journal of Neurovirology 17(2), 166-175. https://doi.org/10.1007/s13365-011-0022-9

Colloca, L., Ludman, T., Bouhassira, D., Baron, R., Dickenson, A.H., Yarnitsky, D. et al. 2017, 'Neuropathic pain', Nature Reviews Disease Primers 3(1), 1-19. https://doi. org/10.1038/nrdp.2017.2

Ellis, R.J., Rosario, D., Clifford, D.B., McArthur, J.C., Simpson, D., Alexander, T. et al., 2010, 'Continued high prevalence and adverse clinical impact of human immunodeficiency virus-associated sensory neuropathy in the era of combination antiretroviral therapy: The CHARTER study', Archives of Neurology 67(5), 552-558. https://doi.org/10.1001/archneurol.2010.76

Evans, S.R., Ellis, R.J., Chen, H., Yeh, T., Lee, A.J., Schifitto, G. et al., 2011, 'Peripheral neuropathy in HIV: Prevalence and risk factors', AIDS (London, England) 25(7) 919-928. https://doi.org/10.1097/QAD.0b013e328345889d

Ferrari, S., Vento, S., Monaco, S., Cavallaro, T., Cainelli, F., Rizzuto, N. et al., 2006 'Human immunodeficiency virus-associated peripheral neuropathies', Mayo Clinic Proceedings 81(2), 213-219.

Keltner, J.R., Vaida, F., Ellis, R.J., Moeller-Bertram, T., Fitzsimmons, C., Duarte, N.A et al., 2012, 'Health-related quality of life 'Well-Being' in HIV distal neuropathic pain is more strongly associated with depression severity than with pain intensity', Psychosomatics 53(4), 380-386. https://doi.org/10.1016/j.psym.2012. 05.002

Konchalard, K. \& Wangphonttanasiri, K., 2007, 'Clinical and electrophysiological evaluation of peripheral neuropathy in a group of HIV infected patients in Thailand', Journal of the Medical Association of Thailand 90(4), 774-781.

Kongsiriwattanakul, S. \& Suankratay, C., 2011, 'Central nervous system infections in HIV-infected patients hospitalized at King Chulalongkorn Memorial Hospital', Journal of the Medical Association of Thailand 94(5), 551-558.

Lucey, B.P., Clifford, D.B., Creighton, J., Edwards, R.R., McArthur, J.C. \& Haythornthwaite, J., 2011, 'Relationship of depression and catastrophizing to pain, disability, and medication adherence in patients with HIV-associated sensory neuropathy', AIDS Care 23(8), 921-928. https://doi.org/10.1080/09540121.2010.543883

Malvar, J., Vaida, F., Sanders, C.F., Atkinson, J.H., Bohannon, W., Keltner, J. et al., 2015 'Predictors of new onset distal neuropathic pain in HIV-infected individuals in the era of combination antiretroviral therapy', Pain 156(4), 731. https://doi.org/10.10 97/01.j.pain.0000461252.75089.bf

Mbuya, S.O., Kwasa, T.O., Amayo, E.O., Kioy, P.G. \& Bhatt, S.M., 1996, 'Peripheral neuropathy in AIDS patients at Kenyatta National Hospital', East African Medical Journal 73(8), 538-540.

Mehta, S.A., Ahmed, A., Kariuki, B.W., Said, S., Omasete, F, Mendillo, M. et al., 2010 Implementation of a validated peripheral neuropathy screening tool in patients receiving antiretroviral therapy in Mombasa, Kenya', The American Journal receiving antiretroviral therapy in Mombasa, Kenya', The American Journal
of Tropical Medicine and Hygiene 83(3), 565-570. https://doi.org/10.4269/ of Tropical Medicin
ajtmh.2010.09-0629

Mehta, S.A., Ahmed, A., Laverty, M., Holzman, R.S., Valentine, F. \& Sivapalasingam, S. 2011 , 'Sex differences in the incidence of peripheral neuropathy among Kenyans 2011, 'Sex differences in the incidence of peripheral neuropathy among Kenyans initiating antiretroviral therapy',
https://doi.org/10.1093/cid/cir432

Nicholas, P.K Mauceri, L, Ciampa, A.S Corless, I.B, Raymond, N., Barry, D.J. et al., 2007 , 'Distal sensory polyneuropathy in the context of HIV/AIDS', Journal of the Association of Nurses in AIDS Care 18(4), 32-40. https://doi.org/10.1016/j. jana.2007.05.003

Sandoval, R., Runft, B. \& Roddey, T., 2010, 'Pilot study: Does lower extremity night splinting assist in the management of painful peripheral neuropathy in the HIV/ AIDS population?', Journal of the International Association of Physicians in AIDS Care 9(6), 368-381. https://doi.org/10.1177/1545109710373828

Saylor, D., Nakigozi, G., Nakasujia, N., Robertson, K., Gray, R., Wawer, M. et al., 2017 'Peripheral neuropathy in HIV-infected and uninfected patients in Rakai, Uganda', Neurology 89(5), 485-491. https://doi.org/10.1212/WNL.0000000000004136

Schifitto, G., McDermott, M.P., McArthur, J.C., Marder, K., Sacktor, N., Epstein, L. et al., 2002, 'Incidence of and risk factors for HIV-associated distal sensory polyneuropathy', Neurology 58(12), 1764-1768. https://doi.org/10.1212/WNL. polyneurop

Shurie, J.S. \& Deribew, A., 2010, 'Assessment of the prevalence of distal symmetrical polyneuropathy and its risk factors among HAART-treated and untreated HIV infected individuals', Ethiopian Medical Journal 48(2), 85-93.

Sithinamsuwan, P., Punthanamongkol, S., Valcour, V., Onsanit, S., Nidhinandana, S. Thitivichianlert, S. et al., 2008, 'Frequency and characteristics of HIV-associated sensory neuropathy among HIV patients in Bangkok, Thailand', Journal of Acquired Immune Deficiency Syndromes (1999) 49(4), 456. https://doi.org/10.1097/QAl. Immune Deficiency

Skopelitis, E.E., Kokotis, P.I., Kontos, P.I., Panayiotakopoulos, G.D., Konstantinou, K. Kordosis, T. et al., 2006, 'Distal sensory polyneuropathy in HIV-positive in the HAART era: An entity underestimated by clinical examination', International Journal of STD and AIDS 17(7), 467-472. https://doi.org/10.1258/095646206777689062 
Smyth, K., Affandi, J.S., McArthur, J.C., Bowtell-Harris, C., Mijch, A.M., Watson, K. et al., 2007, 'Prevalence of and risk factors for HIV-associated neuropathy in Melbourne, Australia 1993-2006', HIV Medicine 8(6), 367-373. https://doi.org/ Melbourne, Australia 1993-2006', H
10.1111/j.1468-1293.2007.00478.x

Song'ony, D.K., 2008, Economic development in Africa in the age of globalization and HIV/AIDS, viewed 23 June 2020, from https://books.google.co.ke/books?id=eZvGLjebs +AND+song\%27ony\&hl=en\&sa=X\&ved=2ahUKEwiW1sqjr6HqAhU4DmMBHReGB zoQ6AEWAHoECAIQAg\#v=onepage $\& q \& \mathrm{f}=$ false.

Taylor, N.F., Dodd, K.J., Shields, N. \& Bruder, A., 2007, 'Therapeutic exercise in physiotherapy practice is beneficial: A summary of systematic reviews 2002-2005', Australian Journal of Physiotherapy 53(1), 7-16. https://doi.org/10.1016/S0004-9514(07)70057-0

Todrys, K.W. \& Amon, J.J., 2009, 'Within but without: Human rights and access to HIV prevention and treatment for internal migrants', Globalization and Health 5(1) 17. https://doi.org/10.1186/1744-8603-5-17

Tumusiime, D.K., Stewart, A., Venter, F.W. \& Musenge, E., 2019, 'The effects of a physiotherapist-led exercise intervention on peripheral neuropathy among people living with HIV on antiretroviral therapy in Kigali, Rwanda', The South African Journal of Physiotherapy 75(1), a1328. https://doi.org/10.4102/sajp.v75i1.1328.

Tumusiime, D.K., Venter, F., Musenge, E. \& Stewart, A., 2014, 'Prevalence of peripheral neuropathy and its associated demographic and health status characteristics, among people on antiretroviral therapy in Rwanda', BMC Public Health 14(1), 1306. https://doi.org/10.1186/1471-2458-14-1306
Wadley, A.L., Cherry, C.L., Price, P. \& Kamerman, P.R., 2011, 'HIV neuropathy risk factors and symptom characterization in Stavudine-exposed South Africans', Journal of Pain and Symptom Management 41(4), 700-706. https://doi.org/ 10.1016/j.jpainsymman.2010.07.006

Wallace, V.C., Blackbeard, J., Pheby, T., Segerdahl, A.R, Davies, M., Hasnie, F. et al., 2007, 'Pharmacological, behavioural and mechanistic analysis of HIV-1 gp120 induced painful neuropathy', Pain $^{\circledast}$ 133(1-3), 47-63. https://doi.org/10.1016/ j.pain.2007.02.015

WHO, 2018, Health of refugees and migrants: Regional situation analysis, practices, experiences, lessons learned and ways forward, WHO Africa Region 2018, viewed 11 July 2019, from https://www.who.int/migrants/publications/AFRO-report. pdf?ua $=1$.

Woldeamanuel, Y.W., Kamerman, P.R., Veliotes, D.G., Phillips, T.J., Asboe, D., Boffito, M et al., 2016, 'Development, validation, and field-testing of an instrument for clinical assessment of HIV-associated neuropathy and neuropathic pain in resource-restricted and large population study settings', PLoS One 11(10), e0164994. https://doi.org/10.1371/journal.pone.0164994

Wolfe, G.I. \& Barohn, R.J., 2002, 'Painful peripheral neuropathy', Current Treatment Options in Neurology 4(3), 177-188. https://doi.org/10.1007/s11940-002 0034-0

Wulff, E.A., Wang, A.K. \& Simpson, D.M., 2000, 'HIV-associated peripheral neuropathy', Drugs 59(6), 1251-1260. https://doi.org/10.2165/00003495-200059060-00005 